\title{
PLASMA BONE-SPECIFIC ALKALINE PHOSPHATASE AS AN INDICATOR OF OSTEOBLASTIC ACTIVITY
}

\author{
K. S. LEUNG, K. P. FUNG, A. H. L. SHER, C. K. LI, K. M. LEE
}

From the Prince of Wales Hospital, Hong Kong

The total plasma alkaline phosphatase level has long been recognised as an indicator of osteoblastic activity, but lack of specificity makes it an insensitive index of the progress of disease and the response to treatment. Selective precipitation by wheatgerm lectin allows measurement of the plasma bone-specific alkaline phosphatase.

We measured the plasma levels of this isoenzyme in 170 normal Chinese adolescents and adults, in 49 adults with fractures of a long bone, in 15 patients with osteosarcoma and in 38 patients with osteolytic metastases. The enzyme activity was also determined in 39 patients with liver disease. Of the patients with fractures, $94 \%$ had increased plasma activity during the healing process. The level was also increased in those with osteosarcoma but not in those with osteolytic bone metastases. There was no significant increase in activity in the patients with liver disease.

We conclude that the plasma bone-specific alkaline phosphatase activity is a sensitive and reliable measure of osteoblastic activity.

J Bone Joint Surg [ Br] 1993; 75-B :288-92.

Received 29 April 1992: Accepted 14 July 1992
In many pathological conditions osteoblastic activity is increased and its measurement is useful in monitoring the healing or progress of the disease. The plasma concentration of alkaline phosphatase is one of the biochemical indicators of bone formation (Moss 1987; Hyldstrup et al 1988; Oni et al 1989) but it is derived from several tissues and its measurement lacks specificity (Moss 1986; Wlodarski and Reddi 1986; Brixen et al 1989; Oni et al 1989). Measurement of the level of plasma bone-specific alkaline phosphatase may be a more accurate index of osteoblastic activity. We report the usefulness of the measurement of this isoenzyme (Rosalki and Foo 1984, 1989) in clinical practice.

\section{PATIENTS AND METHODS}

Plasma bone-specific alkaline phosphatase (BSAP) levels were determined in normal adults and in patients with fractures, bone-forming and non-bone-forming tumours, and hepatitis and cirrhosis.

Control group. This consisted of 170 normal Chinese adolescents and adults (92 males and 78 females) with no past history or present signs or symptoms of bone or liver disease.

Fracture group. Forty-nine adult patients with closed fractures of a single long bone were treated by closed reduction and external immobilisation with plasters or braces, or by closed intramedullary nailing. The fractures were followed to union by serial radiography at 2, 6, 12 and 24 weeks. Plasma BSAP was measured at these intervals.

Tumour group. This consisted of 15 patients with osteosarcoma and 38 with osteolytic bone metastases from malignant tumours in other tissues (nasopharyngeal 5; breast 8; lung 8; unknown 17).

Liver disease group. In this group there were 25 patients with cirrhosis of the liver and 14 with hepatocellular carcinoma.

Determination of total alkaline phosphatase activity. Blood samples were collected in heparinised bottles and centrifuged immediately at $1000 \mathrm{~g}$ for 15 minutes. The plasma was stored at $-70^{\circ} \mathrm{C}$. The total plasma alkaline phosphatase activity was determined with the COBAS 


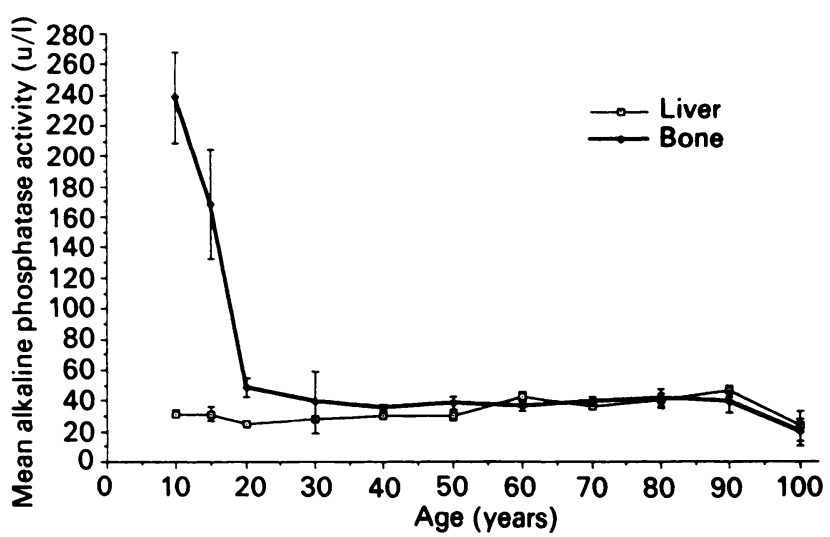

Fig. 1

Mean levels of bone and liver alkaline phosphatase activity in the plasma of normal adolescent and adult males (error bar $=$ SEM).

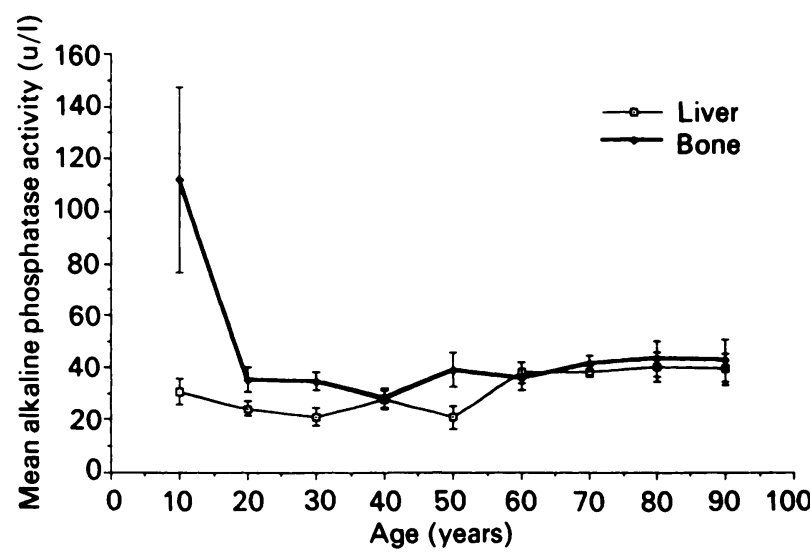

Fig. 3

Mean levels of bone and liver alkaline phosphatase activity in the plasma of normal adolescent and adult females (error bar $=$ SEM).

Biochrom Analyser (Hoffmann-La Roche Ltd, Basle, Switzerland) using $p$-nitrophenyl phosphate substrate in kinetic alkaline phosphatase buffer solution (American Monitor Corporation).

Determination of bone-specific alkaline phosphatase activity. The precipitation procedure was that described by Rosalki and Foo $(1984,1989)$ as modified by Behr and Barnert (1986). A solution containing $40 \mathrm{~g} / 1$ of Triton X100 (Scintran, BDH Chemical Ltd, Poole, UK) and $5 \mathrm{~g} / 1$ of wheatgerm lectin (Sigma Chemical Co, St Louis, MO, USA) was prepared. From this $100 \mu / 1$ were incubated with a similar amount of sample plasma at $37^{\circ} \mathrm{C}$ for 30 minutes. The plasma mixture was then centrifuged at $1000 \mathrm{~g}$ for 10 minutes. The alkaline phosphatase activity of the supernatant was determined as described above. The BSAP activity was then calculated by subtracting the value measured in the supernatant from the total plasma activity. The residual plasma activity was considered to be due to the liver-specific enzyme.

Statistical analysis. The data were analysed using the

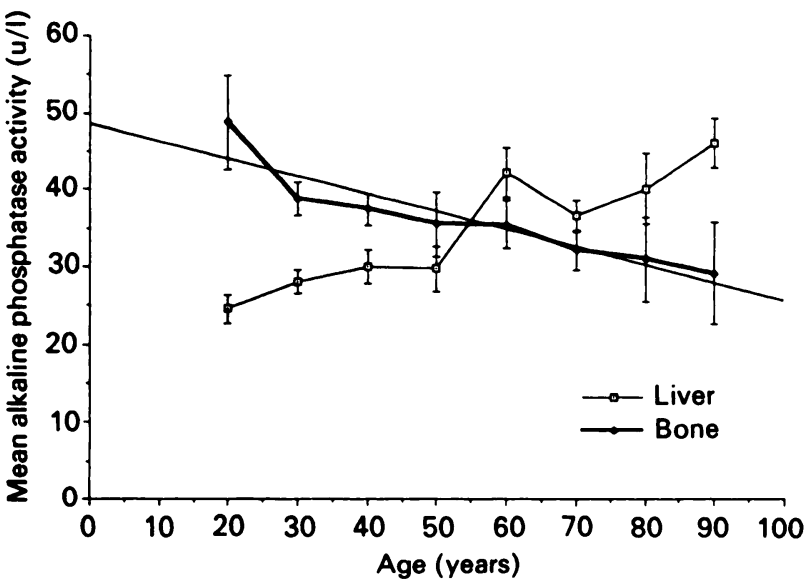

Fig. 2

Mean levels of bone and liver alkaline phosphatase activity in the plasma of normal adult males. The regression line represents the bonespecific enzyme activity $\left(y=48.624-0.22889 \times R^{2}=0.845\right)$.

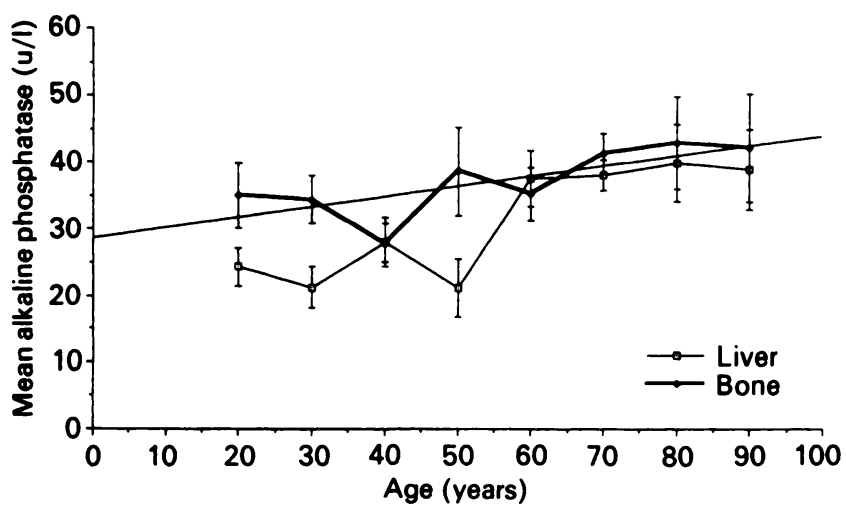

Fig. 4

Mean levels of bone and liver alkaline phosphatase activity in the plasma of normal adult females. The regression line represents the bone-specific enzyme activity $\left(y=28.663+0.1549 x R^{2}=0.561\right)$.

Statisca/Mac program on an Apple Mackintosh LC computer. A scattergram with simple fit was done for the normal ranges. Student's $t$-test was used for the comparison of results and a p value of less than 0.05 was considered to be statistically significant.

\section{RESULTS}

Control group. The plasma BSAP activity in normal Chinese males declines rapidly in adolescence (Fig. 1) and then more gradually with increasing age (Fig. 2). The changes after maturity are not statistically significant $(p>0.05)$. Figures 3 and 4 show the equivalent graphs for females. The gradual increase in activity with age in the adult female population is statistically significant $(p<0.05)$. The mean value of the plasma BSAP activity for adult males was $39.76 \pm 16.68 \mathrm{U} / 1$ and for adult females $31.36 \pm 12.41 \mathrm{U} / 1$. The range is 23 to $56 \mathrm{U} / 1$.

Fracture group. The variations in BSAP activity during fracture healing are shown in Figure 5. The activity 
increased after fracture and a high level persisted during the healing phase in $94 \%$ of patients. The maximum increase was between 8 and 12 weeks after the fracture and significant increases $(p<0.05)$ were observed up to the 15 th week. The levels returned to normal between the 24th and the 30th weeks, corresponding to the clinical and radiological features of healing of the fractures.

Bone tumour group. Figure 6 compares the activity of BSAP and liver-specific alkaline phosphatase in patients with osteosarcoma and in those with non-bone-forming metastatic deposits. In patients with osteosarcoma, the increase in BSAP was statistically significant $(p<0.001)$, whereas the changes in the liver-specific enzyme were not when compared with control values.

In patients with non-bone-forming metastatic tumours (osteolytic lesions), neither form of alkaline phosphatase activity was found to differ significantly from the control values.

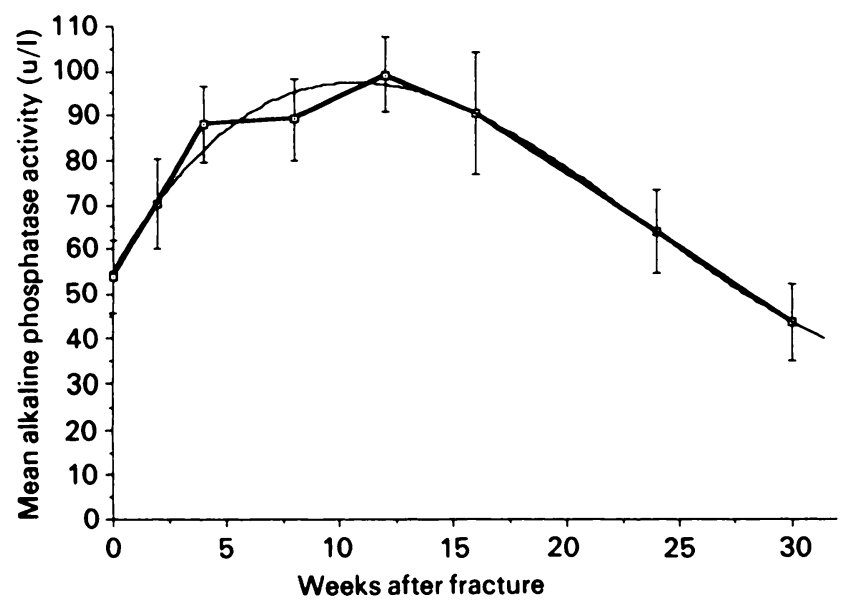

Fig. 5

Mean levels of bone-specific alkaline phosphatase activity in patients during fracture healing. The line is a third-order polynomial curve $(y=$ $\left.55.254+8.8025 x-0.53462 x^{2}+7.6156 e^{-3} x^{3} \cdot R^{2}=0.972\right)$.

Liver disease group. The variations in the activity of BSAP in patients with liver disease were not statistically significant. The activity of liver-specific alkaline phosphatase, however, was significantly increased $(p<0.001)$ (Fig. 7).

\section{DISCUSSION}

Ever since the first descriptions of the relation of alkaline phosphatase to bone mineralisation (Robison 1923; McLean et al 1987; Genge et al 1988; KjaersgaardAndersen et al 1988; Van Straalen et al 1991) and to liver disease (Kay 1929; Roberts 1930; Moss 1982), measurement of its plasma concentration has been a common laboratory test. The major sources of the enzyme in the plasma are bone and liver (Moss 1987) and the total concentration represents the sum of the activity from both. Measurement of the tissue-specific isoenzyme therefore allows us to distinguish between these two sources.

Alkaline phosphatase is a glycoprotein and the boneand liver-specific isoenzymes have a similar structure. The difference between them is a post-translational modification (Komoda 1988; Meyer-Sabellek, Sinha and Köttgen 1988) of the carbohydrate side chain, which allows differentiation between the two enzymes in the plasma. Methods for their quantitative differentiation, however, based on electrophoretic separation, radioimmunoassay, heat inactivation and other techniques are either inaccurate, tedious or impractical (Shephard, Peake and Walmsley 1986; Gonchoroff et al 1991). In this study we used the simple method of Rosalki and Foo $(1984,1989)$ with selective precipitation of the bonespecific isoenzyme by wheatgerm lectin which reacts with the $N$-acetylglucosamine and the $N$-acetylneura-

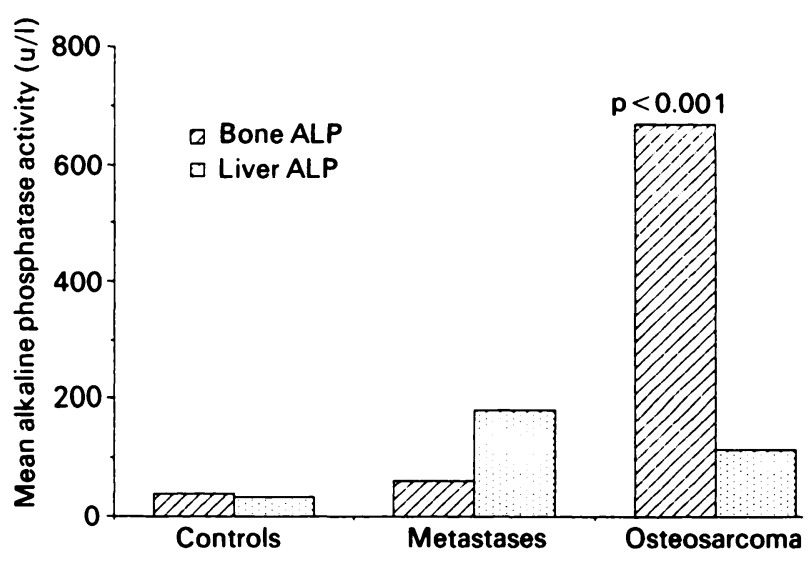

Fig. 6

Mean levels of bone and liver alkaline phosphatase activity in patients with osteosarcoma and with osteolytic bone metastases.

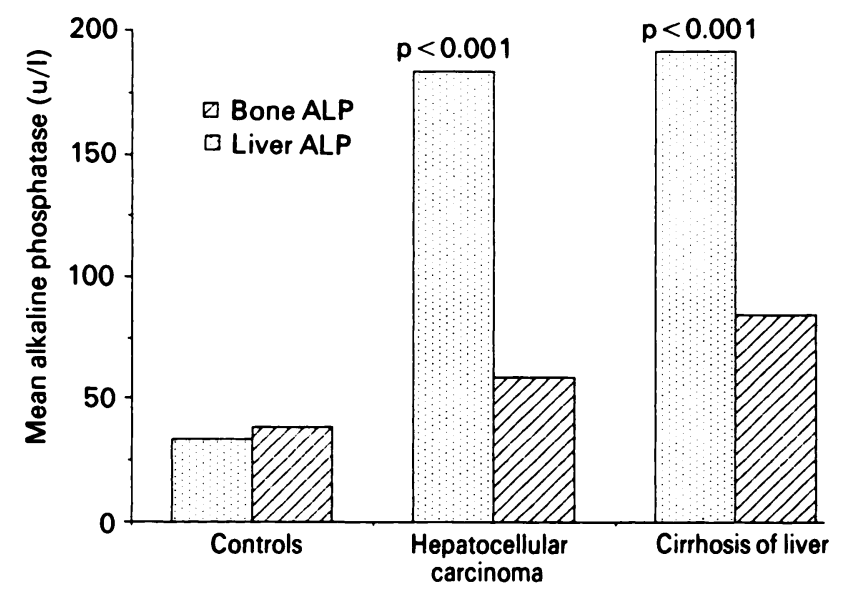

Fig. 7

Mean levels of bone and liver alkaline phosphatase activity in patients with hepatocellular carcinoma and with cirrhosis of the liver. 
minic acid (Lis and Sharon 1973) of the glycoprotein. Selective precipitation of the bone-specific isoenzyme has been well documented (Rosalki and Foo 1984; Behr and Barnert 1986; Steinberg and Rogers 1987; Brixen et al 1989) and has been confirmed by our study.

In the normal population we found very high levels of BSAP activity in adolescents whereas levels of the liver-specific enzyme did not vary from those in adults (Figs 1, 3). In normal women, there was a significant increase in BSAP activity with increasing age but this was less marked in men. The increase in older women may be due to the occurrence of osteoporosis.

Our findings correspond to those of Steinberg and Rogers (1987) and Sørensen (1988), suggesting that the test is reliable and reproducible. The specificity of the test for BSAP is further confirmed by our results from patients with liver disease, in whom increased levels of plasma alkaline phosphatase activity are well known; we could show no significant increase in the BSAP in them.

During fracture healing bone is generated by active osteoblastic activity (Kuhlman 1980; Volpin et al 1986; Deren, Kaplan and Brighton 1990) and the rate of healing is usually assessed by physical and radiological examination. Biochemical monitoring of the healing process has been reported (Kjaersgaard-Andersen et al 1988; Oni et al 1989; Obrant et al 1990), but the determination of total plasma alkaline phosphatase activity has not proved useful. Measurements of the plasma osteocalcin are not practical because of the diurnal variation in its level (Gundberg et al 1985). In our study, the plasma BSAP was significantly increased in patients with closed fractures of the long bones while the liver-specific enzyme was normal. The changes in the plasma activity continued during the healing phase and seem to reflect accurately the osteoblastic activity. Our results, however, were obtained from 49 patients with a variety of fractures treated by several different methods and it is difficult to draw conclusions on the clinical usefulness of the tests from such a heterogeneous group. Further studies with a more uniform sample of patients will show more accurately the diagnostic or prognostic value of this biochemical test.

Total plasma alkaline phosphatase activity has been used to monitor malignant bone tumours (Bacci et al 1987) but lack of specificity, and the common association of increased activity from liver metastases, make the determination of little practical use (Mayne et al 1987). Measurement of the plasma BSAP activity overcomes these problems and may be of great clinical significance. We have shown that in bone-forming tumours such as osteosarcoma, the bone-specific enzyme is very significantly raised and its determination is likely to be useful in evaluating treatment and detecting recurrence (Yoshida et al 1988). Preliminary studies have already shown its sensitivity in detecting tumour recurrence and transformation (Davie, Worsfold and Sharp 1991). In patients with non-bone-forming tumours, contrary to the results of other studies (Shephard et al 1986; Komoda 1988), we found no significant increase in the bone-specific enzyme. This, again, helps in the differential diagnosis of osteosarcoma. In four of our cases in which the histological diagnosis from the biopsy was equivocal the presence of raised plasma BSAP led to the diagnosis of osteosarcoma which was later confirmed from histological examination of the resected tumour.

Conclusion. Selective precipitation of plasma bonespecific alkaline phosphatase by wheatgerm lectin is a simple and reliable method for its quantitative determination. The plasma BSAP level accurately reflects osteoblastic activity and can be useful in the clinical management of fractures and bone tumours.

The authors wish to thank Dr Nancy Leung of the Department of Medicine for supplying the plasma samples from patients with liver disease. We also wish to thank Miss Wendy Yuen for her expert secretarial assistance in preparing this manuscript.

No benefits in any form have been received or will be received from a commercial party related directly or indirectly to the subject of this article.

\section{REFERENCES}

Bacci G, Picci P, Orlandi M, et al. Prognostic value of serum alkaline phosphatase in osteosarcoma. Tumori 1987; 73:331-6.

Behr W, Bamert J. Quantification of bone alkaline phosphatase in serum by precipitation with wheat-germ lectin: a simplified method and its clinical plausibility. Clin Chem 1986; 32:1960-6.

Brixen K, Nielsen HK, Eriksen EF, Charles P, Mosekilde L. Efficacy of wheat germ lectin-precipitated alkaline phosphatase in serum as an estimator of bone mineralization rate: comparison to serum total alkaline phosphatase and serum bone Gla-protein. Calcif Tissue Int 1989; 44:93-8.

Davie MWJ, Worsfold M, Sharp CA. Differential response of serum alkaline phosphatase and serum osteocalcin in Paget's osteosarcoma. Ann Clin Biochem 1991 ; $28: 194-5$.

Deren JA, Kaplan FS, Brighton CT. Alkaline phosphatase production by periosteal cells at various oxygen tensions in vitro. Clin Orthop $1990 ; 252: 307-12$.

Genge BR, Sauer GR, Wu LNY, McLean FM, Wuthier RE. Correlation between loss of alkaline phosphatase activity and accumulation of calcium during matrix vesicle-mediated mineralization. $J$ Biol Chem 1988; 263:18513-9.

Gonchoroff DG, Branum EL, Cedel SL, Riggs BL, O'Brien JF. Clinical evaluation of high-performance affinity chromatography for the separation of bone and liver alkaline phosphatase isoenzymes. Clinica Chimica Acta 1991; $199: 43-50$

Gundberg CM, Markowitz ME, Mizruchi M, Rosen JF. Osteocalcin in human serum: a circadian rhythm. J Clin Endocrinol Metab 1985; 60:736-9.

Hyldstrup L, Clemmensen I, Jensen BA, Transbol I. Non-invasive evaluation of bone formation: measurements of serum alkaline phosphatase, whole body retention of diphosphonate and serum osteocalcin in metabolic bone disorders and thyroid disease. Scan J Clin Lab Invest 1988; $48: 611-9$.

Kay HD. Plasma phosphatase in osteitis deformans and other diseases of bone. Br J Exp Pathol 1929; 10:253-6.

Kjaersgaard-Andersen P, Pedersen P, Kristensen SS, Schmidt SA, Pedersen NW. Serum alkaline phosphatase as an indicator of heterotopic bone formation following total hip arthroplasty. Clin Orthop 1988; $234: 102-9$.

Komoda T. Topics of recent progress for alkaline phosphatase isozymes. Kitasato Arch Exp Med 1988;61:21-8.

Kuhlman RE. Functioning enzyme systems in skeletal tissue and their relationship to structure. In: Urist MR, ed. Fundamental and clinical bone physiology. Philadelphia, etc: JB Lippincott Co, 1980: 172-207.

Lis H, Sharon N. The biochemistry of plant lectins (Phytohemagglutinins). Ann Rev Biochem 1973; 42:541-74. 
Mayne PD, Thakrar S, Rosalki SB, Foo AY, Parbhoo S. Identification of bone and liver metastases from breast cancer by measurement of plasma alkaline phosphatase isoenzyme activity. J Clin Pathol 1987; 40:398-403.

McLean FM, Keller PJ, Genge BR, Walters SA, Wuthier RE. Disposition of preformed mineral in matrix vesicles: internal localization and association with alkaline phosphatase. J Biol B Chem 1987; 262:10481-8.

Meyer-Sabellek W, Sinha P, Köttgen E. Alkaline phosphatase: laboratory and clinical implications. J Chromatogr 1988; 429: 419-44.

Moss DW. Alkaline phosphatase isoenzymes. Clin Chem 1982; 28 : 2007-16.

Moss DW. Multiple forms of acid and alkaline phosphatases: genetics, expression and tissue-specific modification. Clin Chim Acta 1986; $161: 123-35$

Moss DW. Diagnostic aspects of alkaline phosphatase and its isoenzymes. Clin Biochem 1987; 20:225-30.

Obrant KJ, Merle B, Bejui J, Delmas PD. Serum bone-gla protein after fracture. Clin Orthop 1990; 258:300-3.

Oni OOA, Mahabir JP, Iqbal SJ, Gregg PJ. Serum osteocalcin and total alkaline phosphatase levels as prognostic indicators in tibial shaft fractures. Injury 1989; 20:37-8.

Roberts WM. Variations in the phosphatase activity of the blood in disease. Br J Exp Pathol 1930; 11 :90-5.

Robison R. The possible significance of hexosephosphoric esters in ossification. Biochem J 1923; 17:286-93.
Rosalki SB, Foo AY. Two new methods for separating and quantifying bone and liver alkaline phosphatase isoenzymes in plasma. Clin Chem 1984; 30:1182-6.

Rosalki SB, Foo AY. Effect of triton X-100 on precipitation of biliary phosphatase by wheat-germ lectin (letter). Clin Chem 1989; 35:513.

Shephard MDS, Peake MJ, Walmsley RN. Quantitative method for determining serum alkaline phosphatase isoenzyme activity II. Development and clinical application of method for measuring four serum alkaline phosphatase isoenzymes. J Clin Pathol 1986; 39:1031-8.

Serensen S. Wheat-germ agglutinin method for measuring bone and liver isoenzymes of alkaline phosphatase assessed in postmenopausal osteoporosis. Clin Chem 1988; 34:1636-40.

Steinberg KK, Rogers TN. Alkaline phosphatase isoenzymes and osteocalcin in serum of normal subjects. Ann Clin Lab Sci 1987; 17:241-50.

Van Straalen JP, Sanders E, Prummel MF, Sanders GTB. Bone-alkaline phosphatase as indicator of bone formation. Clinica Chimica Acta $1991 ; 201: 27-34$.

Volpin G, Rees JA, Ali SY, Bentley G. Distribution of alkaline phosphatase activity in experimentally produced callus in rats. $J$ Bone Joint Surg [ Br] 1986; 68-B:629-34.

Wlodarski KH, Reddi AH. Alkaline phosphatase as a marker of osteoinductive cells. Calcif Tissue Int 1986; 39:382-5.

Yoshida H, Adachi H, Hamada Y, et al. Osteosarcoma: ultrastructural and immunohistochemical studies on alkaline phosphatasepositive tumor cells constituting a variety of histologic types. Acta Pathol Jpn 1988; 38:325-8. 